\title{
Jazidas de granito marrom imperial causam impactos ambientais na cidade de Bom Jardim- Pernambuco-Brasil
}

\author{
Imperial brown granite quarries cause environmentalimpacts in Bom Jardim- Pernambuco, \\ Brazil.
}

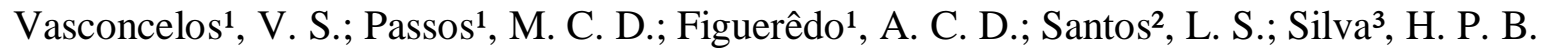 \\ vivianne_paty@hotmail.com
}

\section{RESUMO}

No Brasil o ato de minerar iniciou na época da colonização portuguesa, com a extração do ouro e de outros minerais preciosos, prevalecendo até hoje, fazendo com o que o país seja um dos maiores produtores de minérios, muitas vezes sem a preocupação com os possíveis impactos ao meio ambiente. No município de Bom Jardim, localizado no agreste pernambucano, sobre o Planalto da Borborema, encontramos jazidas de rochas ornamentais, aonde o ambiente vem sendo impactado, levando a perdas ambientais através da extração de granito. Esse trabalho tem por objetivo identificar e analisar os principais problemas ambientais causados por esta extração no município, explicando os fatores e impactos na tentativa de buscar soluções que venham contribuir para a melhoria local, para que essa extração possa ser realizada de forma sustentável. A pesquisa fundamenta-se, basicamente, em análises feitas em pesquisas bibliográficas e visitas a campo. Como resultados, observamos que os maiores impactos (degradação e poluição do solo, do ar e remoção da vegetação) são realizados, principalmente, pelos trabalhadores que atuam de maneira ilegal, já a empresa mineradora que atua no município, em entrevista afirmou que realiza a extração de forma legal cumprindo com todos os requisitos previsto pela Legislação Ambiental.

\begin{abstract}
In Brazil the act of mining began at the time of Portuguese colonization, with the extraction of gold and other precious minerals, prevailing today, causing what the country is a major producer of minerals, often without concern for the possible environmental impacts. In the city of BomJardim, located in rural Pernambuco, on the Plateau of Borborema, we find deposits of ornamental rocks, where the environment has been impacted, leading to environmental losses by granite extraction. This work aims to identify and analyze the main environmental problems caused by this extraction in the county, explaining the factors and impacts in an attempt to find solutions that contribute to the local improvement, so that extraction can be carried out sustainably. The research is based primarily on analyzes made in bibliographic research and field visits. As a result, we found that the greatest impact (degradation and pollution of soil, air and vegetation removal) are carried out mainly by workers who work illegally, since the mining company that operates in the city, in an interview said that performs extraction legally complying with all the requirements laid down by environmental legislation.
\end{abstract}

Keywords:BomJardim; granite; environmental problems.

Palavras-chave: Bom Jardim; granito; Problemas ambientais.

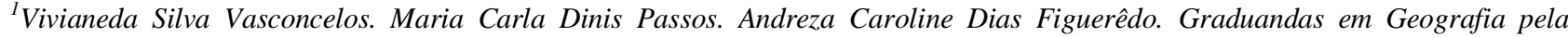
Universidade de Pernambuco, Nazaré da Mata-PE, Brasil.
}

${ }^{2}$ Linaldo Severino dos Santos. Bolsista de Fixação de Técnico, Universidade Federal de Pernambuco/ FACEPE, Recife-PE Brasil.

${ }^{3}$ Helena Paula de Barros Silva. Curso de Licenciatura em Geografia, Universidade de Pernambuco, Nazaré da Mata -PE, Brasil. Programa de Pós-Graduação em Tecnologias Ambientais-ITEP-PE. 


\section{INTRODUÇÃO}

A mineração é sem dúvida uma atividade indispensável à sobrevivência do homem moderno, dada a importância assumida pelos bens minerais em praticamente todas as atividades humanas das mais básicas como habitação, construção, saneamento básico, transporte, agricultura às mais sofisticadas como tecnologia de ponta nas áreas de comunicação e medicina. Ao mesmo tempo, apresenta-se como um desafio para o conceito de desenvolvimento sustentável, uma vez que retira da natureza recursos exauríveis, ou seja, recursos que não se renovam (DIAS, 1999).

Segundo o Ministério do Meio Ambiente, o Brasil é um dos maiores produtores mundiais de recursos minerais e a conciliação da exploração econômica do bem mineral com a conservação ambiental é um pressuposto da gestão ambiental no país.

Segundo Medeiros (1998), apud Mendes (2002), o Estado de Pernambuco está inserido na Província Borborema, cuja evolução é marcada por uma grande mobilidade tectônica, com alternância de regimes compressivos e distensivos, responsáveis pela geração de abundantes jazidas de rochas não orientadas (granitóide) e movimentadas (ortognaisses e migmatitos), sendo essas rochas dominantes em toda aregião Agreste e na Zona da Mata do Estado de Pernambuco.

A mineração do granito marrom imperial em Bom Jardim teve início há cerca de 30 anos, pela empresa Minérios de Bom Jardim, S.A., que implantou a lavra e a unidade de beneficiamento. Sendo este tipo do granito destinado, principalmente, para o mercado externo. A extração de granito é realizada também, na maioria dos locais, informalmente, não há aplicação da legislação mineral.

É perceptível que, no referido Município, os processos de extração se dão sem nenhuma observância às normas legais, causando diversos impactos ambientais, dentre eles: modificação da vegetação, do solo e do ar, além disso, existe também o problema social introduzido pela extração, onde ocorre a presença de crianças trabalhando inclusive sem nenhuma proteção.

Dessa forma, o objetivo da pesquisa foi investigar os principais impactos ambientais causados no município de Bom Jardim-PE, oriundos da extração do granito marrom imperial em jazidas que estejam em processo de desativação. Uma vez que a visitação e o levantamento de dados nessas jazidas apresentam-se de forma mais segura. 


\section{METODOLOGIA}

A metodologia utilizada para o desenvolvimento da pesquisa foi exploratória, explicativa e de caráter descritivo e qualitativo, baseada nas observações realizadas in loco, bem como pesquisas bibliográficas e análise de dados encontrados nos locais visitados.

Quanto a pesquisa bibliográfica, as principais fontes de dados foram adquiridas a partir de leituras de teses e dissertações, livros, artigos e periódicos, além de pesquisa em sites como o Departamento Nacional de Produção Mineral - DNPM e o Núcleo de Avaliação e Pesquisa Educacional - NAPE.

Para verificação dos principais impactos ambientais oriundos do processo de mineração, foram realizadas visitas a jazidas desativadas no município, com o objetivo de verificar se as mesmas atendiam as principais características de uma mineradora em fase de desativação segundo Sánchez (2008), apresentando: Retaludamento e implantação de sistema de drenagem; Preenchimento de escavações; Fechamento do acesso a aberturas subterrâneas e sinalização; Revegetação e recuperação de áreas degradadas; Desmontagem das instalações elétricas e mecânicas, Remoção de insumos e resíduos; Demolição de edifícios; Dispensa da mão de obra e Supervisão e monitoramento pós-operacional.

\section{RESULTADOS E DISCUSSÃO}

Desde o pretérito o homem busca utilizar do meio natural para a sua sobrevivência, desde as habitações em cavernas até a contemporaneidade, sem pensar nas consequências de suas ações por seu uso exacerbado, visto que o meio natural é a única forma de riqueza da espécie humana. Com a mineração não foi diferente, ela sempre esteve presente na história da humanidade, seja como fontede sobrevivência ou como meio de riqueza. Pode-se destacar diferentes tipos de minérios no mundo, mas focaremos no Brasil, onde essa prática é mais intensa devido a sua formação rochosa muito antiga, sendo privilegiado por diferentes tipos de minerais, e também representando boa participação na economia do país.

No Brasil pode-se destacar alguns estados que se sobressaem na exploração de minério, como o estado do Pará, no norte do país, alvo também de inúmeros discussões 
na área. Porém, é em Bom Jardim, município do agreste pernambucano que se encontra a Jazida de Minério Imperial, que há décadas teve seu processo de extração e atualmente também contribui para a movimentação econômica do município.

O Município de Bom Jardim está localizado a uma distância média da capital de $110 \mathrm{~km}$, encontra-se inserido na mesorregião Agreste e na microrregião Médio do Capibaribe do Estado de Pernambuco, limitando-se em Norte com Orobó e Machados, a Sul com João Alfredo, a Leste com Vicência e Limoeiro, e a Oeste com Surubim e Casinhas. O Povoado desenvolveu-se no entorno de uma capela em homenagem a Santa Ana. Teve como seus primeiros habitantes mercadores de algodão do Sertão da Paraíba, com grande movimento de tropeiros que buscavam o algodão bruto em Campina Grande para beneficiá-lo no Recife.É um município que ficou conhecido como a cidade Marrom Imperial, denominação decorrente do minério lá presente.

Município relativamente pequeno quando comparado a sua extensão territorial e áreas ocupadas, Bom Jardim se destacou por sua produção de granito marrom imperial, o que durante determinada década gerou empregos para muitos. Atualmente, Bom Jardim conta com apenas uma mineradora autorizada (figura 1) e, constam em média 80 trabalhadores assalariados, todos de Bom Jardim, e sua atividade ocorrem de forma intensa, utilizando tratores, perfuratrizes com dinamites e máquinas de fio diamantizado para deixar a rocha mais polida. As rochas desse minério são vendidas tanto no Brasil como no exterior, sendo seu maior comprador a China, que compram em formas de blocos.

A distribuição do uso de rochas ornamentais no Brasil, ressalta-se que $40 \%$ são utilizadas em pisos, $25 \%$ em revestimento externo, $12 \%$ em arte funerária, $8 \% \mathrm{em}$ escadas e hall e $6 \%$ em trabalhos estruturais. A demanda por esses materiais é determinada em função da cor, homogeneidade, movimentação e beleza, entre outras características (SOUZA, 2008). 


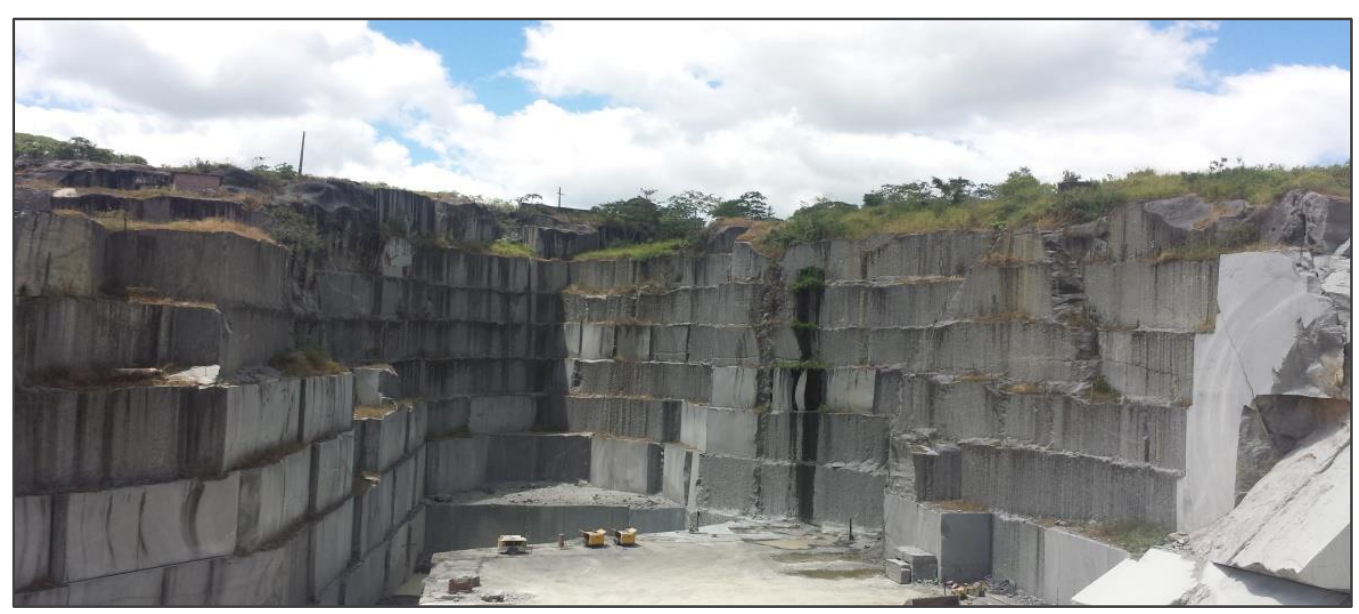

Figura 1: Mineradora autorizada em Bom Jardim-PE. Foto: Vasconcelos, 2015

Com a produção econômica vieram também grandes problemas. Com base em alguns procedimentos metodológicos, e com uma metodologia qualitativa, quantitativa e numa triangulação de dados, foi possível ter embasamento teórico suficiente para determinar e defender uma tese na qual consta as jazidas de minério no município de Bom Jardim como um grande impacto ambiental, onde suas atividades degradam o local, causando malefícios a população residente em suas proximidades e demais entornos do local.

Várias são as consequências de tal atividade na objetividade do lucro, entre elas poluição hídrica, poluição sonora, poluição do ar, sendo a poluição visual mais visível, onde grandes crateras são formadas, causando também danos ao solo que já se apresenta bastante fragilizado (figura 2).

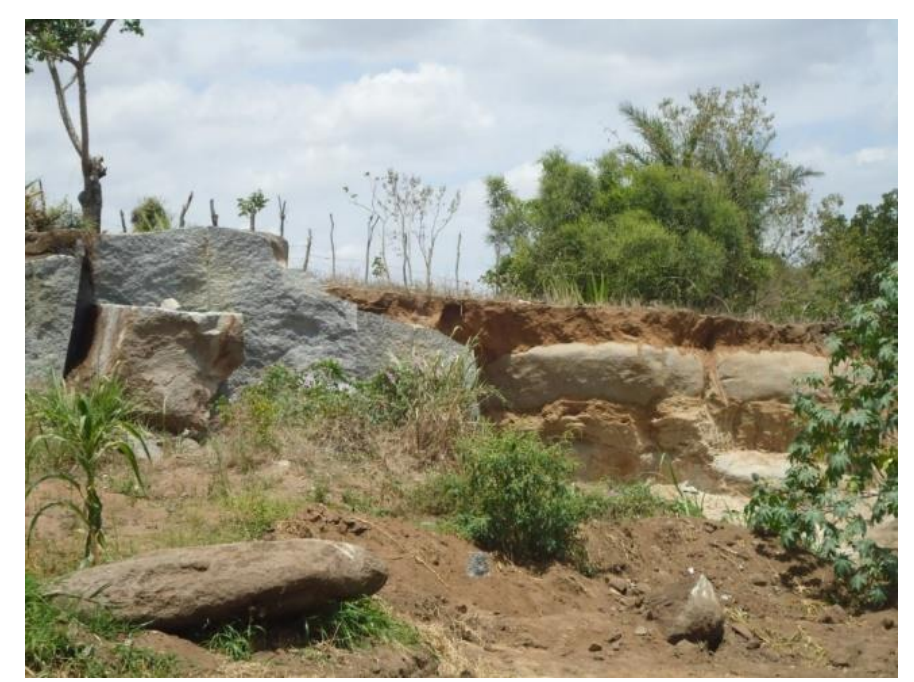

Figura 2: Pedreira desativada do Granito, Bom Jardim- PE. Foto: Vasconcelos, 2015. 
Os resultados obtidos são claros e alarmantes diante das condições ambientais na qual está propícia as atividades das jazidas, assim como também a saúde humana da população que reside nas proximidades. A exploração de granito marrom imperial trouxe grandes benefícios ao município, visto que a exportação também é um dos elementos de sua pauta, porém os danos ambientais são presentes e irreparáveis, e essa discussão deve-se fazer presente não apenas em âmbito acadêmico e sim nas demais instâncias, principalmente no alerta a população local para que estejam cientes dos malefícios causados pela Jazida que não traz apenas benefícios econômicos, também traz consigo o incansável debate do cuidado e preservação dos nossos recursos naturais.

A degradação dos recursos minerais é alvo de grandes discussões, pois está comprometendo a qualidade de vida das pessoas, sendo necessário a busca por práticas sustentáveis, e uso racional desses recursos, porém esse discurso se depara com um capitalismo vigente, detentor dos modos de produção, e coloca em xeque o desenvolvimento sustentável diante da lucratividade. De acordo com o artigo 225 da Constituição Federal, todos têm direito ao meio ambiente ecologicamente equilibrado, bem de uso comum do povo e essencial à sadia qualidade de vida, impondo-se ao poder público e à coletividade o dever de defendê-lo e preservá-lo para as futuras gerações.

A prática sustentável e ações que visam à integridade ambiental é o principal intuito do determinado estudo, visto que se torna necessário reverter a atual situação no município e repensar na forma de exploração e a busca a menos danos ambientais e a integridade física se tornam essenciais e devem ser colocadas em pauta e utilizar de projetos e por conseguintes ações para que o papel seja desempenhado com sucesso.

A recuperação de áreas degradadas pela extração é um dos métodos mais debatidos e essenciais na conjuntura ambiental que se encontra degradada diante do capitalismo imposto sobre os recursos naturais.

De acordo com a Constituição de 1988 , parágrafo $2^{\circ}$ do artigo 255 , se torna obrigação recuperar o meio ambiente degradado por exploração de recursos minerais, um grande avanço que permitiu cobrar e fiscalizar a forma que as empresas atuam com o meio ambiente, e o que fazem para recuperá-lo. A sustentabilidade não se restringe apenas a recuperação de áreas degradas, e sim ver que essas empresas agora passam agir de forma moderada, consciente, com implantação de alguns projetos. 
Nas analises realizadas in loco, não foram identificadas nenhuma das características proposta por Sánchez (2008), sendo identificadas apenas poluição sonora, visual, da água, ar e solo, impactos sobre a fauna e a flora, assoreamento erosão, mobilização da terra, instabilidade de taludes, lançamentos de fragmentos e vibrações, que corroboram com estudos propostos por Franco (1998) e Barreto (2001).

O debate acerca deve ser mantido, a discussão deve ser levada a outras instâncias, e o conhecimento sobre tal problemática propagada e analisada para melhor revogação e tomada de outras medidas que visem à sustentabilidade e o desenvolvimento econômico sem grandes danos aos recursos naturais, visto que eles não são duráveis e são uma herança pertencente à humanidade, da qual a espécie humana toma como fundamental para a sua sobrevivência, assim como também de outras espécies.

Em adição podem ser citados alguns exemplos de como algumas empresas podem agir de forma sustentável:

- Exploração dos recursos minerais (petróleo, carvão, minérios) de forma controlada, racionalizada e com planejamento.

- Criação de atitudes pessoais e empresariais voltadas para a reciclagem de resíduos sólidos. Esta ação além de gerar renda e diminuir a quantidade de lixo no solo, possibilita a diminuição da retirada de recursos minerais do solo.

- Uso de fontes de energia limpas e renováveis (eólica, geotérmica e hidráulica) para diminuir o consumo de combustíveis fósseis. Esta ação, além de preservar as reservas de recursos minerais, visa diminuir a poluição do ar.

- Desenvolvimento da gestão sustentável nas empresas para diminuir o desperdício de matéria-prima e desenvolvimento de produtos com baixo consumo de energia.

- Atitudes voltadas para o consumo controlado de água, evitando ao máximo o desperdício. Adoção de medidas que visem a não poluição dos recursos hídricos, assim como a despoluição daqueles que se encontram poluídos ou contaminados. 


\section{CONSIDERAÇÕES FINAIS}

No que diz respeito ao respeito ao Meio Ambiente, reza o art. 225 da Constituição Federal de 1988, em seu $\S 2^{\circ}$ que: “Aquele que explorar recursos minerais fica obrigado a recuperar o meio ambiente degradado, de acordo com solução técnica exigida pelo órgão competente na forma da Lei.”. No entanto, nas áreas de atividades informais de extração não existe nenhuma recuperação do ambiente degradado e inexiste fiscalização do órgão competente.

Diante do exposto, concluiu-se que, apesar dos impactos trazidos pela mineração (degradação e poluição do solo, do ar e remoção da vegetação) a questão social e ambiental pode ser resolvida através da aplicação da legislação ambiental e da consciência de que os recursos naturais são finitos.

\section{REFERENCIAS}

BARRETO, M. L. (Ed.). Mineração e desenvolvimento sustentável: desafios para o Brasil. Rio de Janeiro: CETEM/MCT, 2001. 215p.

FUIGUEIREDO, B. R. Minérios e Ambiente. Campinas, Unicamp, 2000, 401p.

DIAS, M.do C. O. (Coord). PEREIRA, M. C. B.; DIAS, P. L.F.; VIRGÍNIO, J. F.Manual de Impactos Ambientais. Fortaleza: Banco do Nordeste, 1999.

FRANCO, H. RPPN ameaçada na Serra dos Pirineus, Parabólicas, Instituto Socioambiental, ano 4, n. 34 (nov.), p.7, 1998.

MACHADO, I. F. O meio ambiente e a mineração. In: Economia mineral do Brasil. Coord. Barboza, F. L. M. E GURMENDI, A. C. Brasília: DNPM. 1995.

MENDES, V. A. Rochas Ornamentais de Pernambuco - Encontro Ítalo-Brasileiro de Rochas Ornamentais, 1., 2002, Recife. Palestra Proferida na sede da FIEPE.

SÁNCHEZ, L.E..Avaliação de Impactos Ambientais, conceitos e métodos. Editora Oficina de textos. 2008. 
SOUZA, Valdemir Cavalcanti de. Diagnóstico do setor de rochas ornamentais e de revestimento do Estado de Pernambuco.UFPE - PPGE. Minas. Recife, 2008.

Extração de granito em Bom Jardim-PE: Impacto sócio econômico e efeitos diversos sobre a população residente no entorno de uma jazida. Disponível em: <http://relatosinteressantes.blogspot.com.br/2012/04/extracao-de-granito-em-bomjardim-pe.html> Acesso em 16/02/16

FARIAS, Carlos Eugenio Gomes. Mineração e meio ambiente no Brasil. Disponível em:

< http://www.em.ufop.br/ceamb/petamb/cariboost files/miner c3 a7 c3 a3o 20e 20m eio_20ambiente.pdf> Acesso em 16/02/2016

Revista Espaço da Sophia. Impactos Ambientais causados por mineração. Disponível em: 〈http://www.registro.unesp.br/sites/museu/basededados/arquivos/00000429.pdf > Acesso em 02/03/2016

Diagnostico do setor de rochas ornamentais e de revestimento do estado de Pernmabuco. Disponível em: $<$ https://www.ufpe.br/ppgeminas/images/word/valdemir_cavalcanti.pdf >Acesso em $02 / 03 / 16$

Recebido em: 14/08/2016

Aceito para publicação em: 01/10/2016 